\title{
Support for maternal manipulation of developmental nutrition in a facultatively eusocial bee, Megalopta genalis (Halictidae)
}

\author{
Karen M. Kapheim • Sandra P. Bernal • \\ Adam R. Smith • Peter Nonacs • William T. Wcislo
}

Received: 19 November 2010 /Revised: 6 December 2010 / Accepted: 8 December 2010 /Published online: 6 January 2011

(C) The Author(s) 2011. This article is published with open access at Springerlink.com

\begin{abstract}
Developmental maternal effects are a potentially important source of phenotypic variation, but they can be difficult to distinguish from other environmental factors. This is an important distinction within the context of social evolution, because if variation in offspring helping behavior is due to maternal manipulation, social selection may act on maternal phenotypes, as well as those of offspring. Factors correlated with social castes have been linked to variation in developmental nutrition, which might provide opportunity for females to manipulate the social behavior of their offspring. Megalopta genalis is a mass-provisioning facultatively eusocial sweat bee for which production of males and females in social and solitary nests is concurrent and asynchronous. Female offspring may become either gynes (reproductive dispersers) or workers (non-reproductive helpers). We predicted that if maternal manipulation plays a role in $M$. genalis caste determination, investment in daughters should vary more than for sons. The mass and protein content of pollen stores provided to female offspring varied significantly more than those of males, but volume and sugar content did not. Sugar content varied more among female eggs in social nests than in solitary nests. Provisions were larger, with higher nutrient content,
\end{abstract}

Communicated by L. Keller

K. M. Kapheim $(\bowtie) \cdot$ P. Nonacs

Department of Ecology and Evolutionary Biology,

University of California, Los Angeles,

621 Charles E. Young Dr. South,

Los Angeles, CA 90095, USA

e-mail: kapheimk@ucla.edu

S. P. Bernal • A. R. Smith • W. T. Wcislo

Smithsonian Tropical Research Institute,

MRC 0580-12, Unit 9100, Box 0948,

DPO, AA 34002-9998, USA for female eggs and in social nests. Adult females and males show different patterns of allometry, and their investment ratio ranged from 1.23 to 1.69 . Adult body weight varied more for females than males, possibly reflecting increased variation in maternal investment in female offspring. These differences are consistent with a role for maternal manipulation in the social plasticity observed in M. genalis.

Keywords Megalopta genalis · Maternal effects · Provisioning behavior $\cdot$ Sex investment ratio $\cdot$ Facultative eusociality

\section{Introduction}

Maternal effects contribute to offspring phenotype and may have a significant role in trait evolution (Mousseau and Fox 1998; Wolf and Brodie 1998; Wade 2001; Wilson et al. 2005; Linksvayer 2006; Wolf and Wade 2009). The quantity and quality of nourishment provided to developing offspring shape a wide range of phenotypic traits in diverse taxa (Mousseau and Fox 1998; Reinhold 2002; Mousseau et al. 2009; Russell and Lummaa 2009). These effects may passively reflect environmental conditions that constrain maternal ability to allocate resources to offspring (e.g. see Mousseau and Dingle 1991; Karell et al. 2008). Resource allocation may also result from active maternal behavior, such that mothers evaluate local conditions and differentially distribute the available resources among her offspring, as a form of "parental manipulation" (Alexander 1974). The interests of mother and offspring do not always align, yet these active maternal effects are adaptive if the benefits to the mother outweigh the costs to offspring (Alexander 1974; Michener and Brothers 1974; Craig 1979). 
The key difference between active maternal behavior and passive environmental effects is the source of variation that is available for natural selection. For example, offspring that are under-nourished due to environmental constraints will express traits that are directly selected to make the best of a bad lot. In the case of manipulation, the evolutionary trajectories of offspring traits are indirectly driven through selection on alleles associated with maternal behavior (Craig 1979). It is often difficult to distinguish active from passive effects, and the methods employed in most studies do not allow this level of discrimination (Russell and Lummaa 2009). We investigated the role of active (manipulative) maternal effects relevant to social behavior in a tropical halictid bee by examining variation in offspring investment.

One way social insect queens may manipulate their daughters' social phenotypes is through larval food provisions. Adult body size in Hymenoptera is largely determined by larval nutrition (Klostermeyer et al. 1973; Freeman 1981; Tepedino et al. 1984; Johnson 1988; Molumby 1997; Strohm 2000; Bosch and Vicens 2002). Although body size does not always correlate with fecundity (Tepedino and Torchio 1982; Frohlich and Tepedino 1986; Larsson and Tengö 1989; Müller et al. 1996; Bosch and Vicens 2006; Smith et al. 2009), body size is generally a good predictor of the winner of aggressive dominance interactions between adult females of social species (Eickwort 1986; Packer 1986; Kukuk and May 1988). Workers of facultatively eusocial species are generally smaller than queens, but the size distributions of the two castes usually overlap (Boomsma and Eickwort 1993; Richards and Packer 1994; Coelho 2002; Smith et al. 2008). Previous studies have interpreted differences in body size between castes as evidence for parental manipulation of developmental provisions (Gadagkar et al. 1991; Hunt et al. 1997; Karsai and Hunt 2002; Keeping 2002; but see Richards and Packer 1994). However, seasonal differences in resource availability, photoperiod and temperature, along with the additional foraging efforts of workers during gyne production, may all contribute to differences in body size variance between castes in some species (Kamm 1974; Boomsma and Eickwort 1993). Therefore, observational studies of bivoltine species living in temperate regions are prone to confounding the relative roles of active maternal manipulation and passive maternal effects on body size.

Most previous studies of parental manipulation have focused on the quantity of developmental provisions, with less emphasis on their quality. Nutrient composition may shape physiological aspects of social caste via activating effects of protein consumption on juvenile hormone, which triggers vitellogenesis (Bell 1973), and sugar consumption, which is linked to differences in fat stores among castes (Gadagkar et al. 1991; Richards and Packer 1994).
Megalopta genalis (Halictidae) is particularly well-suited to explore the importance of maternal manipulation. Approximately $25-50 \%$ of females have eusocial nests, with one or a few of the female progeny staying as foraging workers to help rear their siblings, while other nest-founding females remain solitary, with all offspring dispersing (Smith et al. 2003; Wcislo et al. 2004; Smith et al. 2007). Nests with and without workers are often found in the same location, and male and female (both workers and gynes) offspring are produced concurrently throughout the tropical dry and early wet seasons, when reproductive activity is highest and asynchronous (Smith et al. 2007). This suggests variance in larval nutrition is not merely a consequence of local or seasonal differences in resource availability.

M. genalis collect nectar and pollen from more than 65 different plant species, and typically use one to four species to mass provision individual brood cells with food for developing larvae (Roulston 1997; Smith et al., unpublished data). Given that pollen varies greatly in its nutrient composition (Roulston and Cane 2000), females could possibly vary the size and nutrient quality of offspring provisions. On average $M$. genalis workers tend to be smaller than their reproductive nestmate, but there is considerable overlap between workers and queens at the population level and body size does not correlate with reproductive rate in nest foundresses (Smith et al. 2008; Smith et al. 2009). This suggests that the link between body size and social caste may be mediated through additional factors such as dispersal ability, behavioral dominance interactions, fat and protein stores, or endocrine factors, all of which are likely to be sensitive to nutritional inputs during development.

We investigated parental manipulation by measuring the variance of maternal investment in female and male offspring. The potential benefits for a mother that accrue from manipulating her offspring are likely to be asymmetrical for sons versus daughters. From a queen's perspective, there is likely to be a single optimal investment level in sons, assuming no size-based reproductive tactics (Smith and Fretwell 1974). Although M. genalis mating behavior is undescribed, there is no basis to suspect alternative mating strategies (and hence multiple optima). Alternative male strategies are relatively uncommon in sweat bees, and typically are associated with macrocephalic dimorphism (Kukuk and Schwarz 1988; Kukuk 1996 and references therein), which does not occur in M. genalis. A female can, therefore, increase her own reproductive success by maximizing that of her sons. Social insect queens, however, can benefit from having both daughter "workers" and reproductive daughter "gynes," as long as the production of a worker is offset by increased production of sons or gynes, or increased overall nest survival (Queller 1989). If worker behavior is the product of indirect selection via maternal 
investment, then there should be a higher degree of variation in overall investment in female offspring relative to males, corresponding to larger variation in potential life histories. We tested this prediction by characterizing developmental provisions and adult body size of males and females collected at the same time and location, so that external environmental variation was not likely to contribute systematically to the observed variance in male investment relative to female investment.

\section{Methods}

\section{Collections}

Pollen provisions were collected from intact, sealed cells that contained an egg and pollen mass from natural and observation nests of M. genalis on Barro Colorado Island (BCI), Republic of Panama, from February to May 2009 (see Smith et al. 2009 for details). Natural nests are found in dead sticks and woody vines suspended from branch tangles throughout the BCI forest (see Wcislo et al. 2004 for details). Observation nests were constructed by sandwiching a $1 \mathrm{~cm}$ piece of balsa wood between two panes of transparent acrylic to represent natural stick nests, but permit visual inspection of the nest interior. A single, newly emerged female was placed in each nest, which was covered with opaque plastic and hung under plastic roofs in the BCI forest. These nests were monitored for reproductive and social behavior for several months, and were not manipulated in any way. Eggs were preserved in $95 \%$ ethanol, and eggs and pollen were stored at $-20^{\circ} \mathrm{C}$ until analysis. We assessed the status of brood in each cell and number of adults present in the nest to determine the likelihood that cells were provisioned by a single foundress (the mother) or by multiple provisioners (mothers and daughters). The former were called solitary nests and the latter called social nests. We could infer the social status of 21 solitary and eight social nests based on direct observation of the nest from the time they were initiated until they were collected. Other nests were assigned to the solitary category if there was only one adult female present at the time of collection and if there was no evidence that any offspring had emerged prior to collection. This was a conservative definition of solitary nests, but ensured that we did not include formerly social nests that had lost their workers. Social nests were identified as those nests with more than one adult female present at the time of collection. Provisions supplied to both male and female eggs from solitary and social nests were collected throughout the study period, ensuring that any between-sex differences would not be the result of seasonal patterns of resource availability (Fig. 1).

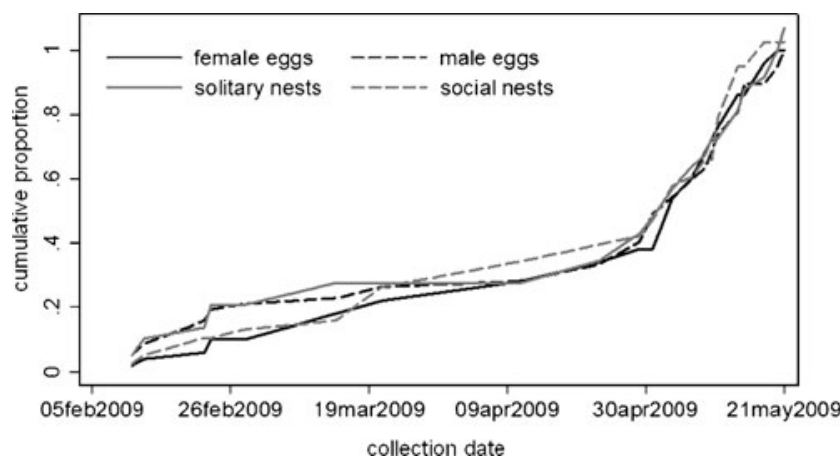

Fig. 1 Cumulative distribution function of collection dates for female (solid black line) and male (dashed black line) provision samples throughout the study period, as well as social (gray solid line) and solitary (gray dashed line) nests. Collection dates were not significantly different for pollen provided to eggs of each sex $\left(\chi^{2}=9.01\right.$, $n=107, p=0.17)$ or for social and solitary nests $\left(\chi^{2}=2.25, n=96\right.$, $p=0.13$ )

We collected both male $(n=63)$ and female $(n=61)$ adult bees of unknown age from natural nests at the end of the dry season April-May 2009. Some of the males were newly emerged bees that had been reared from the brood cells of these nests in tissue culture trays under ambient conditions. However, it was likely that most of the adult males from natural nests were newly emerged or very young, because males usually remain in their natal nests for only a few days after emergence from their brood cell. Although we did not analyze any lab-reared newly emerged females, it is likely that some of the adult females collected from natural nests were also newly emerged. Therefore, adult females likely spanned a greater range of ages, nutritional status, and overall condition than adult males. This could artificially increase the observed variation in dry weight in females with respect to males if dry weight is correlated with any of these parameters. To mitigate this potential bias, we also included dry weights from an additional 20 males and 20 females collected at light traps April-May in 2001, which summed to a total of 83 males and 81 females. These specimens were preserved in $70 \%$ ethanol and Kahle's fixative and stored at $-20^{\circ} \mathrm{C}$ from the time of collection until weighing. These adults are all of unknown age and behavioral history.

Analysis of developmental provisions

\section{Volume and mass}

We measured volume, dry weight, sugar content and protein content for the provisions (pollen masses) of 107 cells. Provisions were divided into two parts before drying at $50^{\circ} \mathrm{C}$ for $48 \mathrm{~h}$. A subset of provisions was dried for an additional $48 \mathrm{~h}$ to ensure drying time was adequate. After weighing, one portion was stored in a sealed plastic bag at $-80^{\circ} \mathrm{C}$ for protein 
analysis. The second portion was re-suspended in $200 \mu \mathrm{l} \mathrm{H} 2 \mathrm{O}$ and stored at $-80^{\circ} \mathrm{C}$ for sugar analysis.

\section{Sugar analysis}

We followed methods described by Richards and Packer (1994) to quantify sugar content. Frozen samples were thawed in a $50^{\circ} \mathrm{C}$ water bath for $3 \mathrm{~min}$ and then centrifuged for $5 \mathrm{~min}$ at $>2,500 \mathrm{rpms}$. A $20-\mu \mathrm{l}$ aliquot of the supernatant containing dissolved sugar was then used in a Leica refractometer (model \#7531 L) to obtain degrees Brix $\left({ }^{\circ} \mathrm{B}\right)$ - the dissolved sugar mass ratio of a solution. To convert this to mass of sugar in the entire provision, we used the National Bureau of Standards Table 114 (1942) to determine the quantity of sugar in each $20-\mu 1$ aliquot, based on its ${ }^{\circ} \mathrm{B}$ and the given density of sugar at $20^{\circ} \mathrm{C}$. All measurements were taken in the same facility between 0800 and 1300 hours at $18-21^{\circ} \mathrm{C}$. We multiplied this quantity by ten to get the quantity of sugar in the $200-\mu l$ solution of sugar water. We divided the latter quantity by the dry mass of the sample portion, and applied this fraction to the mass of the entire provision to get the total sugar content in each provision.

One potential complication to this method is that adding sugar to water changes the volume of the solution, meaning that the supernatant from which the $20-\mu 1$ aliquot was drawn was slightly more than $200 \mu$ l. This could potentially inflate the calculations of sugar content for larger provision samples. To determine how this would affect our results, we quantified the change in solution volume for a range of sugar quantities that reflected the minimum and maximum of our results. Adding $28.4 \mathrm{mg}$ of sugar to $200 \mu \mathrm{l}$ of water increases the volume by $10.5 \mu \mathrm{l}$ and inflates the calculation of sugar content by $1.5 \mathrm{mg}(1.7 \%)$. Volume increases by only $0.5 \mu \mathrm{l}$ when $1.8 \mathrm{mg}$ of sugar is added, and does not have a measurable effect on sugar content calculations. However, variation in sugar content of provisions for males and females were not significantly different (see "Results"), so our conclusions are unlikely to be affected by this complication.

\section{Protein analysis}

We used nitrogen $(\mathrm{N})$ analysis of provision samples to estimate protein content. $\mathrm{N}$ analysis was performed by Brookside Laboratories, Inc. (New Knoxville, $\mathrm{OH}$ ) using combustion and thermal conductivity detection in a CarlErba total nitrogen analyzer (AOAC International 1996; Gavlak et al. 2003). Percent crude protein was calculated from N\% with the standard conversion factor of $6.25 \%$. Percent protein was then applied to the total dry weight of each provision to determine total protein content of each provision sample.
Sex determination of eggs

DNA was extracted from approximately half of each egg by homogenizing each sample in PBS buffer and then using a QiaAmp DNA Mini-Kit (QIAGEN). DNA was amplified with PCR and genotyped according to the protocol described in Kapheim et al. (2009).

We determined the sex of all eggs based on heterozygosity at an initial set of four microsatellite markers - $\mathrm{mg} 4, \mathrm{mg}$, mg30, and mg44 (Kapheim et al. 2009). Individuals with only one allele across the four loci are likely to be haploid males. The probability that a diploid female would be homozygous at every typed loci was calculated following Paxton et al. (2000). Using observed levels of heterozygosity from Kapheim et al. (2009), we found the probability that a diploid individual would be homozygous at all four loci is $<0.0001$. Most individuals that we classified as males were successfully genotyped at all four loci. Two individuals (one male and one female) were classified based on three loci, but probability of being heterozygous at one or more of these loci was $>0.999$, so there is low uncertainty about their sex assignment. Diploidy was not detected in a set of 81 known males genotyped for a separate study (K. M. Kapheim, unpublished data). We genotyped 14 eggs at two additional loci ( 45 and $46 \mathrm{mg}$ ) to resolve ambiguities in genotypes from the first four loci.

\section{Adult bee measurements}

Adult bees collected in 2009 were stored at $-20^{\circ} \mathrm{C}$ until they were dried for $48 \mathrm{~h}$ at $60^{\circ} \mathrm{C}$. A subset of these bees was dried for an additional $48 \mathrm{~h}$ to ensure drying time and temperature was adequate. After weighing, head width and intertegular width were measured under a dissecting microscope at $\times 20$ magnification fitted with a lens micrometer by three different observers (KMK, SPB, and ARS). The average of these measurements was used in all analyses.

\section{Statistical analyses}

All statistical analyses were done in Stata (v. 9.2). We used Mann-Whitney $U$ tests to evaluate differences in median values between male and female offspring provisions, provisions found in social and solitary nests, and adult male and female body measurements, due to deviations from normality in each of these parameters.

To test for differences in the variation due to sex and sociality, we made used of mixed modeling techniques to model regression with heteroskedastic residual errors, with maximum likelihood estimation method. Ordinary least squares regression assumes variance of the residuals is constant across observations. We, therefore, used a special case of the linear mixed model to explore residual variance 
as a multiplicative linear function of the predictor variables (Harvey 1976; Guierrez 2008). The expected mean of each outcome variable $\left(y_{t}\right)$ was modeled as:

$y_{i}=\beta_{0}+\beta_{1} X_{1}+\beta_{2} X_{2}+\cdots+\beta_{n} X_{n}+\varepsilon_{t}$

and the residual variance was simultaneously modeled as:

$\ln \left[V\left(\varepsilon_{t}\right)\right]=\alpha_{0}+\alpha_{1} z_{1}+\alpha_{2} z_{2}+\cdots \alpha_{k} z_{k}$

The estimated variance of the residuals (variance components) were derived from this model within each sex-social class using maximum likelihood methods (Harvey 1976), and compared for differences. Although variance tends to scale with mean, explicitly modeling the residual variance as a multiplicative linear function allows us to explore the possibility that there is additional variance beyond that correlated with differences in mean. We used a likelihood ratio test to determine whether the assumption of residual heteroskedasticity significantly improved the model (Harvey 1976).

The expected mean of provision volume was modeled by provision dry weight, sex of egg laid on provision, nest social status, and an interaction between sociality and sex. Residual variance was simultaneously modeled by sex, sociality, and their interaction. Expected mean of provision dry weight was modeled by provision volume, sex of egg laid on provision, and nest social status. Residual variance simultaneously modeled by sex and sociality. The interaction term was left out of the dry weight model, because the model could not converge with its inclusion. Upon inspection of the variance components, it was clear that so much of the variance was explained by the main effects, that the interaction term was not a significant source of variance.

Expected means of provision protein content and sugar content were modeled by provision dry weight, sex of egg laid on provision, and social status of nest. The residual variance of each of these outcome variables was modeled by sex, sociality, and their interaction.

The expected mean of adult dry weight and its residual variance were simultaneously modeled by sex. Adult body size was based on head width, and was modeled by dry weight, intertegular width, sex, and an interaction between intertegular width and sex. The residual variance of head width was simultaneously modeled by sex.

\section{Results}

Developmental provisions

We collected 20 provision/egg combinations from 18 observation nests and 87 provision/egg combinations from
79 natural nests. This included ten sibling pairs $(4 \mathrm{~m}-\mathrm{m}$, $4 \mathrm{f}-\mathrm{f}, 2 \mathrm{~m}-\mathrm{f}$ ), collected from the same nest on the same day. Sibling pairs occur in relatively low frequency compared with unrelated individuals in our dataset, so we did not consider nest as a factor in our analysis. Of 107 eggs, 50 were diploid (female) and 57 were haploid (male). Of the female eggs, 23 were collected from nests that likely had only a single provisioner (solitary nests), and 21 were collected from nests that likely had more than one provisioner (social nests). The remaining six could not be reliably assigned, so were left out of analyses that included sociality. Of the male eggs, 35 were collected from solitary nests and 17 were collected from social nests, with the remaining five dropped from relevant analyses. Social and solitary nests, as well as female and male eggs were collected in equal proportions throughout the study period $\left(\chi_{\text {social }}{ }^{2}=2.25, n=96, p=0.13 ; \chi_{\text {sex }}{ }^{2}=9.01, n=107 p=0.17\right.$; Fig. 1). Provision weight did not vary with date of collection, indicating that seasonal effects were not important within the study period $\left(F=0.09 ; r^{2}=0.001\right.$; $p=0.76 ; n=107)$.

Fertilized (female) eggs were found on significantly larger provisions (in dry weight and volume) than were male eggs $\left(Z_{\text {weight }}=5.10-p<0.0001 ; n=96 ; Z_{\text {volume }}=\right.$ $4.75-p<0.0001 ; n=96$; Table 1$)$. The provisions found in social nests were significantly larger than those found in solitary nests $\left(Z_{\text {weight }}=-5.56-p<0.0001 ; n=96\right.$; $Z_{\text {volume }}=-5.15-p<0.0001 ; n=96$; Table 1$)$. The sugar and protein content found within pollen provisions was also significantly higher for female provisions $\left(Z_{\text {sugar }}=\right.$ $3.02-p<0.003 ; n=96 ; Z_{\text {protein }}=4.58-p<0.0001 ; n=95$; Table 1$)$ and in social nests $\left(Z_{\text {sugar }}=-2.47-p<0.01\right.$; $n=96 ; Z_{\text {volume }}=-5.70-p<0.0001 ; n=95$; Table 1$)$.

Total volume, sex of egg, and social status of the nest were significant predictors of dry weight in the heteroskedastic regression $\left(Z_{\text {volume }}=17.02-p<0.0001 ; n=96\right.$; $Z_{\text {sex }}=3.10-p=0.002 ; n=96 ; Z_{\text {social }}=-3.06-p=0.002$; $n=96$; Table 2). Including all of these factors in an ordinary linear regression produced similar results and explained $89 \%$ of the variance in dry weight $(F=236.86 ; n=96$; $r^{2}=0.89 ; n=96 ; p<0.0001$ ). A likelihood ratio test on the regression with and without the assumption of heteroskedasticity reveals that including heteroskedasticity significantly improves the model $\left(\chi^{2}=7.52-p=0.02 ; d f=2\right)$. Estimated variance components were lowest for provisions made for male eggs in social nests, and highest for provisions made for female eggs in solitary nests (Fig. 2a). The difference in variance between dry weight of pollen masses provided to male and female eggs was significantly different from zero $(Z=9.48-p<0.0001$; $n=96$; Table 2). Differences in variance between provisions found in social and solitary nests, however, was not significant $(Z=0.61 — p=0.55 ; n=96)$. 
Table 1 Summary statistics for offspring provisions and adult body measurements
Provision measurements are based on 44 females ( 23 from solitary nests and 21 from social nests) and 52 males (35 from solitary nests and 17 from social nests). Adult body size measurements are based on 61 females and 63 males. Adult dry weight measurements are based on 81 females and 83 males. The additional 20 individuals were collected in 2001 at light traps on BCI. Differences between sexes and sociality were determined with a Mann-Whitney $U$ test

\begin{tabular}{|c|c|c|c|c|}
\hline & Females & Males & Sex differences & Social differences \\
\hline \multicolumn{5}{|l|}{ Pollen masses } \\
\hline \multicolumn{5}{|l|}{ Provision dry weight (mg) } \\
\hline Solitary nests & $64.37 \pm 20.73$ & $47.61 \pm 9.21$ & $Z=5.10$ & $Z=-5.56$ \\
\hline Social nests & $94.50 \pm 18.68$ & $67.01 \pm 17.04$ & $p<0.0001$ & $p<0.0001$ \\
\hline \multicolumn{5}{|l|}{ Provision volume (ml) } \\
\hline Solitary nests & $0.14 \pm 0.04$ & $0.10 \pm 0.03$ & $Z=4.75$ & $Z=-5.15$ \\
\hline Social nests & $0.22 \pm 0.05$ & $0.15 \pm 0.05$ & $p<0.0001$ & $p<0.0001$ \\
\hline \multicolumn{5}{|l|}{ Sugar content (mg) } \\
\hline Solitary nests & $11.16 \pm 5.47$ & $8.22 \pm 4.53$ & $Z=3.02$ & $Z=-2.47$ \\
\hline Social nests & $14.48 \pm 6.52$ & $10.19 \pm 5.54$ & $p=0.003$ & $p=0.01$ \\
\hline \multicolumn{5}{|l|}{ Protein content (mg) } \\
\hline Solitary nests & $22.84 \pm 6.89$ & $17.85 \pm 4.11$ & $Z=4.58$ & $Z=-5.70$ \\
\hline Social nests & $35.95 \pm 7.89$ & $25.74 \pm 7.16$ & $p<0.0001$ & $p<0.0001$ \\
\hline \multicolumn{5}{|l|}{ Adult bees } \\
\hline Adult dry weight (mg) & $38.28 \pm 8.91$ & $22.62 \pm 6.56$ & $\begin{array}{l}Z=-9.44 \\
p<0.0001\end{array}$ & - \\
\hline Adult head width (mm) & $4.28 \pm 0.39$ & $3.46 \pm 0.23$ & $\begin{array}{l}Z=-8.93 \\
p<0.0001\end{array}$ & - \\
\hline
\end{tabular}

Dry weight was the only significant factor predicting total volume of pollen masses $\left(Z_{\text {weight }}=16.87-p<0.0001\right.$; $n=96 ; Z_{\mathrm{sex}}=-1.03-p=0.30 ; n=96 ; Z_{\mathrm{soc}}=1.69-p=0.09$; $n=96 ; Z_{\text {intxn }}=1.29-p=0.20 ; n=96 ;$ Table 2$)$. The full model explained $88 \%$ of the variance in an ordinary linear regression $\left(F=159.86 ; r^{2}=0.88 ; p<0.0001 ; n=96\right)$. According to a likelihood ratio test, including heteroskedasticity did not improve the model $\left(\chi^{2}=0.97-p=0.81\right.$; $d f=3)$. Differences in variance between social and solitary nests and the interaction between sex and sociality were significantly different from zero $\left(Z_{\text {social }}=-8.79-p<\right.$ $0.0001 ; n=96 ; Z_{\text {interxn }}=-5.18-p<0.0001 ; n=96$; Table 2 ). However, this is not likely to be a biologically important phenomenon, as the variance components themselves are extremely close to zero (estimated variance components: social females $=3.46 \times 10^{-4}$, solitary females $=5.82 \times$ $10^{-8}, \quad$ social males $=4.98 \times 10^{-14}, \quad$ solitary males $=$ $7.01 \times 10^{-22}$; Fig. 2b). Differences in variance between males and females were not significantly different from zero $\left(Z_{\text {sex }}=-0.03-p=0.976 ; n=96\right)$.

Dry weight was a significant predictor of total sugar found in pollen masses in the heteroskedastic regression model $\left(Z_{\text {weight }}=9.03-p<0.0001 ; n=96 ; Z_{\mathrm{sex}}=0.73-p=0.46 ; n=\right.$ $96 ; Z_{\mathrm{soc}}=-1.83-p=0.07 ; n=96 ; Z_{\mathrm{intxn}}=-0.54-p=0.59 ; n=$ 96; Table 2). The same parameters in an ordinary linear regression explained $50 \%$ of the variation in sugar content $\left(F=22.57 ; r^{2}=0.50 ; \quad p<0.000 ; n=96\right)$. According to a likelihood ratio test, allowing heteroskedasticity of variance

Table 2 Summary of heteroskedastic regression results for characteristics of pollen provisions provided to offspring and adult body size measurements

\begin{tabular}{|c|c|c|c|c|c|c|}
\hline & \multicolumn{4}{|l|}{ Pollen masses } & \multicolumn{2}{|l|}{ Adult bees } \\
\hline & Dry weight & Volume & Sugar & Protein & Head width & $\begin{array}{l}\text { Dry } \\
\text { weight }\end{array}$ \\
\hline Significant predictors & Volume, sex, social & Dry weight & Dry weight & Dry weight & $\begin{array}{l}\text { Intertegular, sex, } \\
\text { intertegular } \times \text { sex }\end{array}$ & Sex \\
\hline Significant differences in variance & Sex & Social, $\operatorname{sex} \times \operatorname{soc}^{a}$ & $\mathrm{SeX} * \operatorname{Soc}$ & Sex & $\operatorname{Sex}^{\mathrm{a}}$ & Sex \\
\hline
\end{tabular}

Top portion of the table identifies significant predictors of each outcome variable and whether there were significant differences among males and females or solitary and social nests. The bottom portion of the table identifies variables for which variance in the trait was significantly different. See text for model parameters and $Z$-scores

${ }^{a}$ Although statistically significant differences were found between social and solitary nests and an interaction between sex and social status for variation in provision mass volume, the estimated variance components were very close to zero, suggesting these differences may not be biologically meaningful. This is also true of differences in variance found between male and female head width 
significantly improved the model $\left(\chi^{2}=8.25-p=0.04 ; d f=3\right)$. Solitary and social females had the lowest estimated variance components, with a significant difference between them $(Z=$ $2.03-p=0.04 ; n=44 ;$ Fig. $2 c$ ). The difference between solitary and social male components of variance, however, were not significantly different $(Z=1.52-p=0.13 ; n=52$; Fig. 2c). The interaction between sex and social status was the only significant variable in the model of residual variance $(Z=4.76-p<0.0001 ; n=96$; Table 2$)$. Differences in variance due to sex and sociality were not significantly different from zero $\left(Z_{\mathrm{sex}}=1.39-p=0.17 ; n=96 ; Z_{\mathrm{soc}}=0.22-p=0.83\right.$; $n=96)$. This suggests that there are significant differences in variance in sugar content of pollen masses provided to female eggs in social and solitary nests, but no differences in the variation for male provisions.

In the regression with heteroskedasticity, dry weight was the only significant predictor of protein content in pollen masses $\left(Z_{\text {weight }}=20.18-p<0.0001 ; n=95 ; Z_{\text {sex }}=-1.62-\right.$ $p=0.11 ; n=95 ; Z_{\mathrm{soc}}=0.95-p=0.34 ; n=95 ; Z_{\mathrm{intxn}}=1.26-$ $p=0.21 ; n=95$; Table 2). These parameters explained $91 \%$ of the variation in protein content in an ordinary linear regression $\left(F=238.81 ; r^{2}=0.91 ; p<0.0001 ; n=95\right)$. The model including heteroskedasticity was a significant improvement from the ordinary linear regression $\left(\chi^{2}=9.81-\right.$ $p=0.02 ; d f=3)$. The difference in variance in protein content of male and female provisions was significantly different from zero $(Z=2.13-p=0.03 ; n=95$; Table 2$)$.
Differences in variance between social and solitary nests and an interaction between sex and sociality were not significant $\left(Z_{\mathrm{soc}}=0.97-p=0.33 ; n=95 ; Z_{\text {intxn }}=0.37-\right.$ $p=0.71 ; n=95)$. The estimated variance components revealed no significant difference in variance of the amount of protein provided to females in social and solitary nests $(Z=-0.87-p=0.39 ; n=95$; Fig. $2 \mathrm{~d})$.

\section{Adult body size}

Female M. genalis are significantly larger than males in dry weight $\left(Z_{\text {weight }}=-9.44-p<0.0001 ; n=164\right.$; Table 1$)$ and head width $\left(Z_{\text {head }}=-8.93-p<0.0001 ; n=121\right.$; Table 1$)$. In the heteroskedastic regression model, body size (head width) is explained by intertegular width $(Z=14.34-p<$ $0.0001 ; n=116$; Table 2$)$, sex $(Z=-6.20-p<0.0001$; $n=116$; Table 2), and an interaction between intertegular width and $\operatorname{sex}(Z=6.72-p<0.0001 ; n=116$; Table 2$)$. The significant interaction term suggests that males and females have different allometries between head and thorax width (Fig. 3). An ordinary linear regression with the same parameters produced similar results and explained $95 \%$ of the variance in body size $\left(F=683.04 ; r^{2}=0.95 ; p<0.0001\right.$; $n=116$ ). The model was not significantly improved by allowing for heteroskedastic variance $\left(\bar{\chi}^{2}=1.26 ; p=0.13\right.$; $d f=0,1)$. Although the differences in variance between males and females were significantly different from zero
Fig. 2 Log transformed estimated variance components $( \pm \mathrm{SE})$ for characteristics of pollen masses provided to male (dark bars) and female (light bars) eggs in solitary and social nests (a dry weight, b volume, c sugar content, and $\mathbf{d}$ protein content). In part (b), the standard error bars have been truncated for visual ease. The actual values are $\mathrm{SE}=-745.47$ for both solitary and social males. Asterisk indicates significant differences in variance
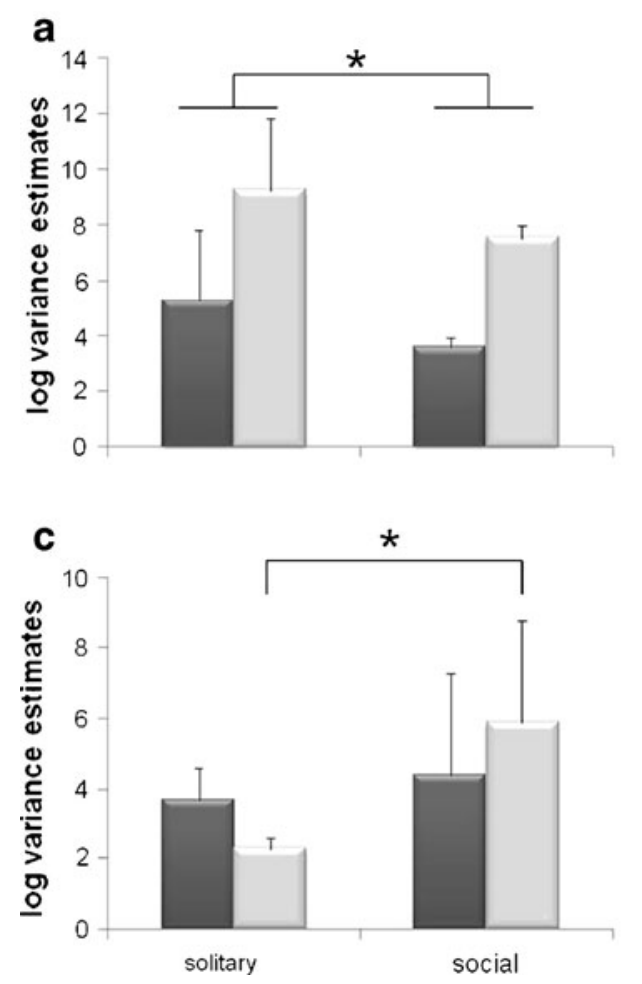

b
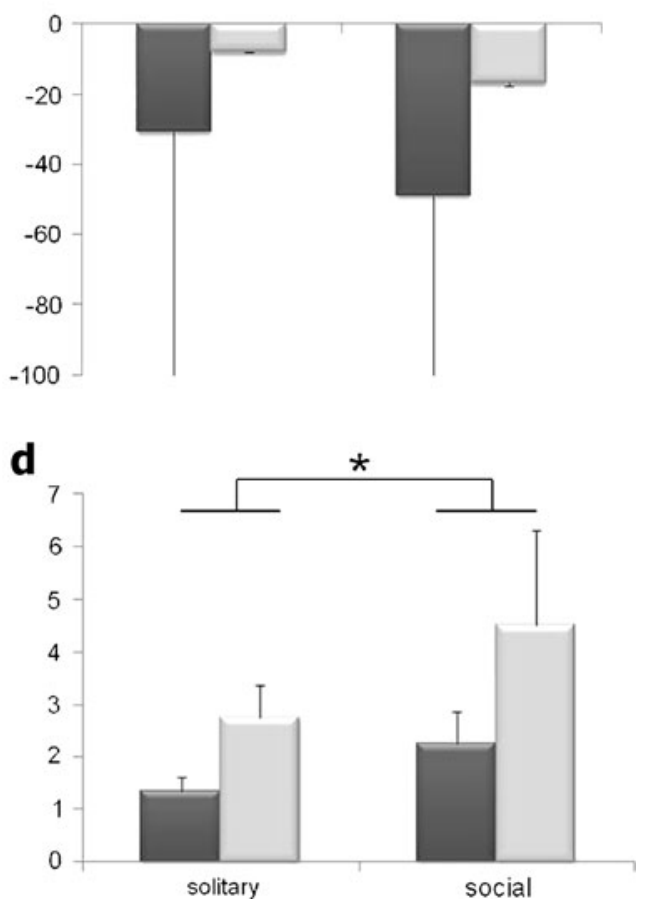


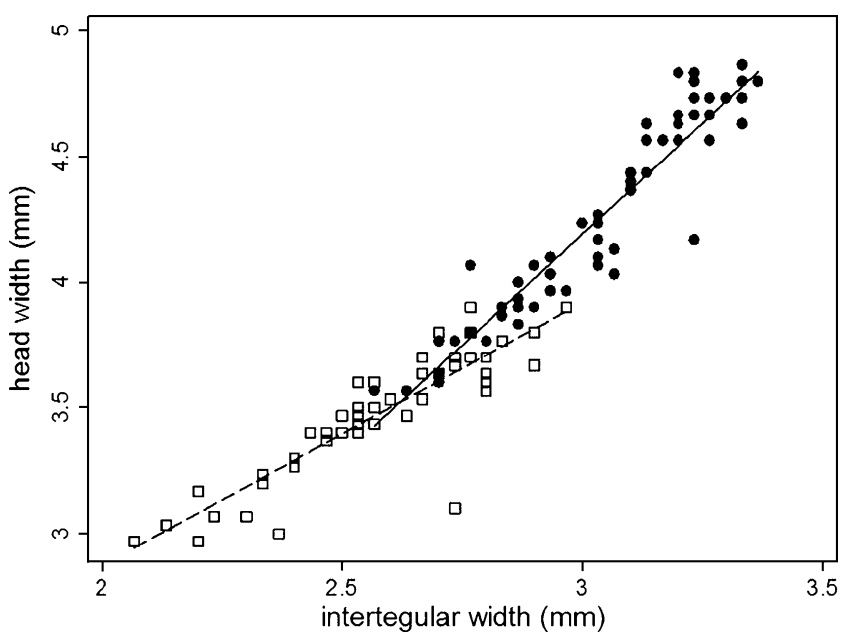

Fig. 3 Adult male (white squares) and female Megalopta genalis (black circles) have different allometries. In a heteroskedastic regression, intertegular width $(Z=14.34 ; p<0.001)$, sex $(Z=-6.20$; $p<0.001)$, and an interaction between intertegular width and $\operatorname{sex}(Z=$ $6.72 ; p<0.001)$ were significant predictors of head width

$(Z=-6.11 ; p<0.0001)$, the estimated variance components were extremely close to zero for both sexes, indicating that differences in the variance in body size is unlikely to be biologically meaningful (estimated variance components: males $=0.01$, females $=4.82 \times 10^{-5}$, Fig. 4a) .

Sex explains $50 \%$ of the variation in adult dry weight in an ordinary linear regression $\left(F=165.01 ; n=164 ; r^{2}=0.50\right.$; $p<0.0001$; Table 2). A likelihood ratio test suggests that adding heteroskedasticity to the variance significantly improves the model $\left(\bar{\chi}^{2}=7.58-p=0.003 ; d f=0,1\right)$. The difference in dry weight variance among adult males and females was significantly different from zero $(Z=9.19-p<$ $0.0001 ; n=164$; Table 2; Fig. 4b), indicating that there is more variation in the size of females than males.

Fig. 4 Log transformed estimated variance components $( \pm \mathrm{SE})$ for adult male (dark bars) and female (light bars) size (a body size and $\mathbf{b}$ dry weight). Asterisk indicates significant differences in variance
Investment ratio estimates

Female offspring cost more to produce than male offspring. Although adult body size measurements and provision sample measurements do not come from the same individuals, dividing the average provision size by the average adult dry weight indicates that female provisions are more efficiently converted to body mass than male provisions ( ratio $_{\text {females }}=$ 2.00; ratio $\left._{\text {males }}=2.38\right)$. We estimated the cost ratio $(\mathrm{F}: \mathrm{M})$ that foundresses experience when investing in daughters and sons. These ranged from 1.23 to 1.69 (Table 3). Given the sex-based allometry patterns in body size and the large age range included in the dry weight dataset, larval provisions appear reflective of the actual cost incurred by foundresses when provisioning female or male eggs.

\section{Discussion}

\section{Maternal manipulation}

There is more variation in the size and protein content of $M$. genalis pollen masses provided to female than male offspring (Fig. 2a, d), suggesting that developmental provisions may be a means of maternal manipulation. Although this study did not explicitly test a mechanism linking developmental nutrition to social behavior, the link between nutrition and reproductive physiology is mediated by endocrine factors ubiquitous among insects (Nijhout and Wheeler 1982; Nijhout 1994; Mirth and Riddiford 2007). Organizational endocrine effects on physiology have been implicated as a developmental switch that leads to differences among social insect castes (West Eberhard 1987; 1996). Evidence for developmental caste-biasing and physiological correlates of caste has been found in M. genalis (Smith et al. 2008; Smith et al. 2009; Kapheim et al., unpublished data), and maternal manipulation of larval diet is a potential mechanism by which these caste-biasing physiological traits emerge.

Protein consumption during development may have potentially important effects on reproductive physiology at emergence, given its known link to reproductive hormones, vitellogenesis, and other factors associated with insect reproduction (Bell 1973; Bitondi and Simoes 1996). In another halictid bee, Lasioglossum zephyrum, offspring body size increased with protein quantity in provisions, independent of total provision size (Roulston and Cane 2002), and body size decreased when bees were fed cattail (Typha) pollen that has a low protein content (Greenberg 1982).

Evidence from other halictid bees indicates that adults can actively manipulate the phenotype of their developing brood based on nutritional inputs. Plateaux-Quénu (1983) (reviewed by Michener 1990) was able to manipulate the 
Table 3 Cost ratio (F/M) estimates of investments made by foundresses when producing daughters versus sons

Provision based estimates

Volume of pollen mass

Dry weight of pollen mass

Adult body size-based estimates

Adult dry weight

sex of eggs laid by adding pollen to the provision masses of Lasioglossum calceatum, suggesting that queens are not only able to recognize differences in pollen quantity, but also to base strategic reproductive decisions on these provisions. Additionally, provision masses and cells of some species (e.g., Halictus ligatus and Lassioglossum umbripenne) are shaped differently for gynes and workers and males, indicating that bees are capable of discriminating between provision masses intended for each caste (Wille and Orozco 1970; Kamm 1974; Boomsma and Eickwort 1993; Richards and Packer 1994).

\section{Alternative hypotheses}

In general, mothers should invest extra resources into the sex for which body size is most closely linked to reproductive success (Trivers and Willard 1973; Charnov et al. 1981; Frank 1995). This alternative hypothesis could potentially explain the observed sex differences in variance if (a) extra provisions (in terms of size and protein) would increase reproductive success in females more than males and (b) foundresses vary in their ability to provide extra resources to daughters. In M. genalis, body size is not directly linked to fecundity (Smith et al. 2009), though it may be correlated with reproductive success in other ways (e.g., ability to found or usurp a nest or compete for access to food). It is unknown how much $M$. genalis foundresses vary in their ability to secure resources. However, the asynchronous and extended reproductive season of the tropics allows for a great deal of flexibility in provisioning behavior. If females are poor foragers, they can make up for this by taking more days to provision a cell until it contains an optimal quantity and quality of food. Data from 3 years of observation nest censuses on BCI show remarkably idiosyncratic variation in the cell-closing patterns of individual females (Kapheim et al. unpublished data). Cells are often left open and partially provisioned for several days, while on other occasions cells are constructed, provisioned, and sealed within 1 or 2 days. Variation found within and among nests in the rate of cell closure (and thus provisioning rate) may be a function of spatial variation in resource availability, but this possibility is not supported by the fact that such rates vary among nests within meters of one another.
Differences among males and females

Pollen masses provided for female eggs varied more than those provided for male eggs in dry weight and protein, but not in volume or sugar content. Nectar is the primary source of sugar and water in a pollen mass, so differences in volume and dry weight would likely reflect the amount of nectar (and thus sugar) in the provisions. This indicates that nectar content does not vary differently among provisions made for each sex. Sex-based differences in variance of dry weight, however, likely reflect differences in variance of pollen added to the provisions, which is the primary protein source.

The homogeneous variance of total volume and amount of sugar in $M$. genalis provisions represents a different pattern than that found in the temperate eusocial sweat bee $H$. ligatus (Richards and Packer 1994). Size and sugar content of H. ligatus gyne provisions are higher than that of worker provisions, though the distributions overlap (Richards and Packer 1994). In temperate species, gynes typically overwinter in diapause before founding a nest the following spring (Yanega 1997), and the ability to do this is directly dependent upon fat stores, which are partially determined by sugar intake during development (Gadagkar et al. 1991). It is therefore possible that sugar content of provisions is not as important in tropical species, like M. genalis, for which diapause is not a stage of the reproductive cycle.

The majority of bees and wasps are sexually dimorphic, with females being larger (O’Neill 1985; Hurlbutt 1987; Stubblefield and Seger 1994; Shreeves and Field 2008). Female M. genalis are, on average, 1.23-1.69 times larger than males (Tables 1 and 3), and within the range of sexual size dimorphism observed in other bees (Danforth 1990; Roulston and Cane 2002; Shreeves and Field 2008). M. genalis males and females have different patterns of cephalic allometry, where head size increases faster in females for every unit increase in intertegular width (Fig. 3). Head size may be more important for females than males, given that increases in head size are presumably linked to mandible and adductor muscle size, which can be beneficial in nest excavation and brood cell construction (Smith and Weller 1989). Moreover, large M. genalis females possess large genal spines that are lacking in smaller females, which may play a role in social competition (Arneson and Wcislo 2003).

\section{Differences among social and solitary nests}

Pollen masses of higher quality are provided for female and male eggs in social nests (Table 1). There is also more variance in the sugar content of provisions for females in social nests than in solitary nests (Fig. 2c). The increased size of the provisions could be the result of a resource surplus due to the extra available foraging effort. This explanation would 
not, however, account for the increased variance in female provisions. Following the central limit theorem, increased numbers of adults on nests should reduce variation in the flow of resources into the nest as the rate regresses to the mean habitat expectation (Wenzel and Pickering 1991).

An alternative social manipulation hypothesis may have to do with workers attempting to maximize their inclusive fitness by rearing more gynes than additional workers and more closely related sisters than brothers (Trivers and Hare 1976; Nonacs 1991). If the sex of the egg laid by a queen is affected by her perceptions of pollen mass, then higher quality provisions may be the workers' attempt to influence their mothers into laying relatively more female eggs. It may, therefore, be in a worker's best interest to provision each cell with a gyne-quality pollen mass to assure that if the egg laid is female, it would maximize her inclusive fitness.

Worker effort to influence the sex of offspring may also explain why there is increased variance in sugar content of female provisions in social nests, but not of dry weight, volume, or protein content. In social nests, queens have the ability to make last minute alterations to pollen masses made by workers immediately prior to laying an egg and cell closure (Batra 1964; Breed and Gamboa 1977). She could easily adjust the protein content by consuming some pollen, and though it may not be as easy to separate nectar out of the provision, she could increase the quantity of nectar. If queens of social nests are manipulating provisions made by workers, this would result in less variation for protein than sugar.

\section{Sex allocation cost ratios}

Sex allocation cost ratios (F/M) ranged from 1.23 to 1.69 . The estimate derived from provision dry weight (1.42) is probably the most accurate. In general, using body weight as a measure of sex investment ratio may be less accurate than direct measures of food provisions in many species of sexually dimorphic Hymenoptera (Trivers and Hare 1976; Boomsma 1989; Helms 1994; Bosch and Vicens 2002). This is likely due to the decreasing efficiency in metabolism per unit body weight with increasing body size (Boomsma 1989; Danforth 1990; Field 1992). The extra fat stores of females may significantly contribute to this phenomenon, although perhaps not as much in species that do not overwinter (Helms 1994). The production to consumption ratio for $M$. genalis is 0.50 (females) and 0.42 (males), indicating that food is converted to adult tissue approximately $8 \%$ more effectively in females than males.

\section{Conclusions}

Developmental maternal effects are a potentially important caste-biasing factor, and may have played a role in the evolution of eusociality. If these maternal effects are in the form of parental manipulation, we should expect variation in female offspring to exceed that of male offspring, independent of resource and other ecological limitations. Variation in the quantity and quality of food provisions provided to developing daughters exceeded those provided to sons in a tropical population of $M$. genalis, where males and females (that can be either gynes or workers) are produced contemporaneously. Developmental nutrition has been linked to reproductive physiology and caste behavior, so these differences may be a means by which female M. genalis actively manipulate some of their daughters, and this manipulation may play an important role in the social plasticity observed in this species. Similar studies in other species, under different sets of environmental conditions, could illuminate whether developmental maternal effects are generally the passive influence of maternal environment or an active maternal strategy, and thus to what degree evolutionary change in offspring traits are governed through an extended phenotype.

Acknowledgements KMK was supported by a Short Term Fellowship from STRI, a Pre-doctoral fellowship from the Smithsonian Institution, a Holmes O. Miller grant and a George Bartholomew fellowship from UCLA EEB, a Joan Wright Goodman award from American Women in Science, a GAANN fellowship from US Department of Education, a graduate fellowship from the Center for Society \& Genetics, and a NSF Doctoral Dissertation Improvement Grant. KMK and PN were also supported by NSF grant IOS-0642085. SPB participated in the STRI Internship Program with general research funds provided to WTW. ARS was supported by a Smithsonian Institution Post-doctoral fellowship. We would like to thank Damien Jose Ramirez Garcia and Timothy Alvey for assistance in the field. Oris Acevedo, Belkys Jimenez, and Orelis Arosemena and the rest of the STRI staff provided valuable logistic support. Rose Medeiros and Xiao Chen of UCLA Academic Technology Services provided statistical advice. Research on BCI was conducted with permission from the Autoridad Nacional del Ambiente under permit \# SEX/A-34-09, in accordance with the laws of the Republic of Panama. We are thankful for the suggestions of three anonymous reviewers that led to improvements in the manuscript.

Conflicts of interest The authors declare that they have no conflict of interest.

Open Access This article is distributed under the terms of the Creative Commons Attribution Noncommercial License which permits any noncommercial use, distribution, and reproduction in any medium, provided the original author(s) and source are credited.

\section{References}

Alexander RD (1974) The evolution of social behavior. Annu Rev Ecol Syst 5:325-383

Arneson L, Wcislo WT (2003) Dominant-subordinate relationships in a facultatively social, nocturnal bee, Megalopta genalis (Hymenoptera: Halictidae). J Kansas Entomol Soc 76:183-193 
Bates, FJ (1942) Polarimetry, saccharimetry, and the sugars. National Bureau of Standards Circular C440, U.S. Government Printing Office, Washington

Batra S (1964) Behavior of the social bee, Lasioglossum zephyrum, within the nest (Hymenoptera: Halictidæ). Insect Soc 11:159185

Bell WJ (1973) Factors controlling initiation of vitellogenesis in a primitively social bee, Lasioglossum zephyrum (Hymenoptera Halictidae). Insect Soc 20:253-260

Bitondi MMG, Simoes ZLP (1996) The relationship between level of pollen in the diet, vitellogenin and juvenile hormone titres in Africanized Apis mellifera workers. J Apicult Res $35: 27-36$

Boomsma JJ (1989) Sex-investment ratios in ants: has female bias been systematically overestimated? Am Nat 133:517-532

Boomsma JJ, Eickwort GC (1993) Colony structure, provisioning and sex allocation in the sweat bee Halictus ligatus (Hymenoptera, Halictidae). Biol J Linn Soc 48:355-377

Bosch J, Vicens N (2002) Body size as an estimator of production costs in a solitary bee. Ecol Entomol 27:129-137

Bosch J, Vicens N (2006) Relationship between body size, provisioning rate, longevity and reproductive success in females of the solitary bee Osmia cornuta. Behav Ecol Sociobiol 60:26-33

Breed MD, Gamboa GJ (1977) Behavioral control of workers by queens in primitively eusocial bees. Science 195:694-696

Charnov EL, Los-den Hartogh RL, Jones WT, van den Assem J (1981) Sex ratio evolution in a variable environment. Nature 289:27-33

Coelho BWT (2002) The biology of the primitively eusocial Augochloropsis iris (Schrottky, 1902) (Hymenoptera, Halictidae). Insect Soc 49:181-190

Craig R (1979) Parental manipulation, kin selection, and the evolution of altruism. Evolution 33:319-334

Danforth BN (1990) Provisioning behavior and the estimation of investment ratios in a solitary bee, Calliopsis (Hypomacrotera) persimilis (Cockerell) (Hymenoptera: Andrenidae). Behav Ecol Sociobiol 27:159-168

Eickwort GC (1986) First steps into eusociality: the sweat bee Dialictus lineatulus. Fla Entomol 69:742-754

Field J (1992) Patterns of nest provisioning and parental investment in the solitary digger wasp Ammophila sabulosa. Ecol Entomol 17:43-51

Frank SA (1995) Sex allocation in solitary bees and wasps. Am Nat 146:316-323

Freeman BE (1981) Parental investment and its ecological consequences in the solitary wasp Sceliphron assimile (Dahlbom) (Sphecidae). Behav Ecol Sociobiol 9:261-268

Frohlich DR, Tepedino VJ (1986) Sex ratio, parental investment, and interparent variability in nesting success in a solitary bee. Evolution 40:142-151

Gadagkar R, Bhagavan S, Chandrashekara K, Vinutha C (1991) The role of larval nutrition in preimaginal biasing of caste in the primitively eusocial wasp Ropalidia marginata (Hymenoptera, Vespidae). Ecol Entomol 16:435-440

Gavlak R, Horneck D, Miller RO, Kotuby-Amacher J (2003) Total nitrogen in botanical materials In: Soil, plant and water reference methods for the western region, 2nd edn. WREP-125, Western Region Extension Publication. p. 2.20

Greenberg L (1982) Year-round culturing and productivity of a sweat bee, Lasioglossum zephyrum (Hymenoptera: Halictidae). J Kansas Entomol Soc 55:13-22

Guierrez RG (2008) Tricks of the trade: getting the most out of xtmixed. In: UK Stata Users Group Meetings 2008. Stata Users Group, London, England. Available at: http://ideas.repec.org/p/ boc/usug08/06.html

Harvey AC (1976) Estimating regression models with multiplicative heteroskedasticity. Econometrica 44:461-465
Helms KR (1994) Sexual size dimorphism and sex ratios in bees and wasps. Am Nat 143:418-434

Hunt JH, Schmidt DK, Mulkey SS, Williams MA (1997) Caste dimorphism in the wasp Epipona guerini (Hymenoptera: Vespidae; Polistinae, Epiponini): further evidence for larval determination. J Kansas Entomol Soc 69:362-369

Hurlbutt B (1987) Sexual size dimorphism in parasitoid wasps. Biol J Linn Soc 30:63-89

AOAC International (1996) AOAC International Official Method 990.03 Protein (crude) in animal feed. In: AOAC Official Methods of Analysis, 16 edn. AOAC International, Gaithersburg. pp 18-19

Johnson MD (1988) The relationship of provision weight to adult weight and sex ratio in the solitary bee, Ceratina calcarata. Ecol Entomol 13:165-170

Kamm DR (1974) Effects of temperature, day length, and number of adults on the sizes of offspring in a primitively social bee. J Kansas Entomol Soc 47:8-18

Kapheim KM, Pollinger JP, Wcislo WT, Wayne RK (2009) Characterization of 12 polymorphic microsatellite markers for a facultatively eusocial sweat bee Megalopta genalis. Mol Ecol Resour 9:1527-1529

Karell P, Kontiainen P, Pietiäinen H, Siitari H, Brommer JE (2008) Maternal effects on offspring Igs and egg size in relation to natural and experimentally improved food supply. Func Ecol 22:682-690

Karsai I, Hunt JH (2002) Food quantity affect traits of offspring in the paper wasp Polistes metricus (Hymenoptera: Vespidae). Environ Entomol 31:99-106

Keeping MG (2002) Reproductive and worker castes in the primitively eusocial wasp Belonogaster petiolata (DeGeer) (Hymenoptera: Vespidae): evidence for pre-imaginal differentiation. J Insect Physiol 48:867-879

Klostermeyer EC, Mech SJ, Rasmussen WB (1973) Sex and weight of Megachile rotundata (Hymenoptera: Megachilidae) progeny associated with provision weights. J Kans Entomol 46:536-548

Kukuk PF (1996) Male dimorphism in Lasioglossum (Chilalictus) hemichalceum: the role of larval nutrition. J Kansas Entomol Soc 69:147-157

Kukuk PF, May BP (1988) Dominance hierarchy in the primitively eusocial bee Lasioglossum (Dialictus) zephyrum: is genealogical relationship important? Anim Behav 36:1848-1850

Kukuk PF, Schwarz M (1988) Macrocephalic male bees as functional reproductives and probable guards. Pan Pac Entomol 64:131-137

Larsson FK, Tengö J (1989) It is not always good to be large; some female fitness components in a temperate digger wasp, Bembix rostrata (Hymenoptera: Sphecidae). J Kansas Entomol Soc 62:490-495

Linksvayer TA (2006) Direct, maternal, and sibsocial genetic effects on individual and colony traits in an ant. Evolution 60:25522561

Michener CD (1990) Reproduction and castes in social halictine bees. In: Engels W (ed) Social insects: An evolutionary approach to castes and reproduction. Springer, New York

Michener CD, Brothers DJ (1974) Were workers of eusocial Hymenoptera initially altruistic or oppressed. Proc Natl Acad Sci USA 71:671-674

Mirth CK, Riddiford LM (2007) Size assessment and growth control: how adult size is determined in insects. Bioessays 29:344-355

Molumby A (1997) Why make daughters larger? Maternal sexallocation and sex-dependent selection for body size in a massprovisioning wasp, Trypoxylon politum. Behav Ecol 8:279-287

Mousseau TA, Dingle H (1991) Maternal effects in insect life histories. Annu Rev Ecol Syst 36:511-534

Mousseau TA, Fox C (1998) Maternal effects as adaptations. Oxford University Press, New York 
Mousseau TA, Uller T, Wapstra E, Badyaev AV (2009) Evolution of maternal effects: past and present. Phil Trans Roy Soc Lond B 364:1035-1038

Müller CB, Blackburn TM, Schmid-Hempel P (1996) Field evidence that host selection by conopid parasitoids is related to host body size. Insect Soc 43:227-233

Nijhout HF (1994) Insect Hormones. Princeton University Press, Princeton

Nijhout HF, Wheeler DE (1982) Juvenile hormone and the physiological basis of insect polymorphisms. Q Rev Biol 57:109

Nonacs P (1991) Alloparental care and eusocial evolution - the limits of Queller head-start advantage. Oikos 61:122-125

O’Neill KM (1985) Egg size, prey size, and sexual size dimorphism in digger wasps (Hymenoptera: Sphecidae). Can JZoolog 63:2187-2193

Packer L (1986) Multiple foundress associations in a temperate population of Halictus ligatus (Hymenoptera, Halictidae). Can J Zool 64:2325-2332

Paxton RJ, Thorén PA, Gyllenstrand N, Tengö J (2000) Microsatellite DNA analysis reveals low diploid male production in a communal bee with inbreeding. Biol J Linn Soc 69:483-502

Plateaux-Quénu C (1983) Le volume d'un pain d'abeille influence-t-il le sexe de l'oeuf pondu sur lui? Etude expérimentale portant sur la premiére couvée d'Evylaeus calceatum (Scop.) (Hym., Halictinae). Ann Sci Nat 5:41-52

Queller DC (1989) The evolution of eusociality-reproductive head starts of workers. Proc Natl Acad Sci USA 86:3224-3226

Reinhold K (2002) Maternal effects and the evolution of behavioral and morphological characters: a literature review indicates the importance of extended maternal care. J Hered 93:400-405

Richards MH, Packer L (1994) Trophic aspects of caste determination in Halictus ligatus, a primitively eusocial sweat bee. Behav Ecol Sociobiol 34:385-391

Roulston TH (1997) Hourly capture of two species of Megalopta (Hymenoptera: Apoidea: Halictidae) at black lights in Panama with notes on nocturnal foraging by bees. J Kansas Entomol Soc 70:189-196

Roulston TH, Cane JH (2000) Pollen nutritional content and digestibility for animals. Plant Syst Evol 222:187-209

Roulston TH, Cane JH (2002) The effect of pollen protein concentration on body size in the sweat bee Lasioglossum zephyrum (Hymenoptera: Apiformes). Evol Ecol 16:49-65

Russell AF, Lummaa V (2009) Maternal effects in cooperative breeders: from Hymenopterans to humans. Phil Trans Roy Soc Lond B 364:1143-1167

Shreeves G, Field J (2008) Parental care and sexual size dimorphism in wasps and bees. Behav Ecol Sociobiol 62:843-852

Smith CC, Fretwell SD (1974) The optimal balance between size and number of offspring. Am Nat 108:499-506

Smith BH, Weller C (1989) Social competition among gynes in halictine bees: the influence of bee size and pheromones on behavior. J Insect Behav 2:397-411

Smith AR, Wcislo WT, O'Donnell S (2003) Assured fitness returns favor sociality in a mass-provisioning sweat bee, Megalopta genalis (Hymenoptera: Halictidae). Behav Ecol Sociobiol 54:14-21

Smith AR, Wcislo WT, O'Donnell S (2007) Survival and productivity benefits to social nesting in the sweat bee Megalopta genalis (Hymenoptera: Halictidae). Behav Ecol Sociobiol 61:1111-1120
Smith A, Wcislo W, O’Donnell S (2008) Body size shapes caste expression, and cleptoparasitism reduces body size in the facultatively eusocial bees Megalopta (Hymenoptera: Halictidae). J Insect Behav 21:394-406

Smith AR, Kapheim KM, O'Donnell S, Wcislo WT (2009) Social competition but not subfertility leads to a division of labour in the facultatively social sweat bee Megalopta genalis (Hymenoptera: Halictidae). Anim Behav 78:1043-1050

Strohm E (2000) Factors affecting body size and fat content in a digger wasp. Oecologia 123:184-191

Stubblefield JW, Seger J (1994) Sexual dimophism in the Hymenoptera. In: Short RV, Balaban E (eds) The differences between the sexes. Cambridge University Press, Cambridge, pp 71-103

Tepedino VJ, Torchio PF (1982) Phenotypic variability in nesting success among Osmia lignaria propinqua females in a glasshouse environment: (Hymenoptera: Megachilidae). Ecol Entomol $7: 453-462$

Tepedino VJ, Thompson R, Torchio PF (1984) Heritability for size in the Megachilid bee Osmia lignaria-Propinqua Cresson. Apidologie 15:83-87

Trivers RL, Hare H (1976) Haplodiploidy and evolution of social insects. Science 191:249-263

Trivers RL, Willard DE (1973) Natural selection of parental ability to vary sex-ratio of offspring. Science 179:90-92

Wade MJ (2001) Maternal effect genes and the evolution of sociality in haplo-diploid organisms. Evolution 55:453-458

Wcislo WT, Arneson L, Roesch K, Gonzalez V, Smith A, Fernandez $\mathrm{H}$ (2004) The evolution of nocturnal behaviour in sweat bees, Megalopta genalis and M. ecuadoria (Hymenoptera: Halictidae): An escape from competitors and enemies? Biol J Linn Soc 83:377-387

Wenzel JW, Pickering J (1991) Cooperative foraging, productivity, and the central limit theorem. Proc Natl Acad Sci USA 88:3738

West Eberhard MJ (1987) Flexible strategy and social evolution. In: Ito Y, Brown JL, Kikkawa J (eds) Animal societies: theories and facts. Japan Scientific Societies Press, Tokyo, pp $35-51$

West Eberhard MJ (1996) Wasp societies as microcosms for the study of development and evolution. In: Turillazzi S, West Eberhard MJ (eds) Natural history and evolution of paper wasps. Oxford University Press, Oxford, pp 290-317

Wille A, Orozco E (1970) The life cycle and behavior of the social bee Lassioglossum (Dialictus) umbripenne (Hymenoptera: Halictidae). Rev Biol Trop 17:199-245

Wilson AJ, Coltman DW, Pemberton JM, Overall ADJ, Byrne KA, Kruuk LEB (2005) Maternal genetic effects set the potential for evolution in a free-living vertebrate population. J Evol Biol $18: 405-414$

Wolf JB, Brodie ED (1998) The coadaptation of parental and offspring characters. Evolution 52:299-308

Wolf JB, Wade MJ (2009) What are maternal effects (and what are they not)? Phil Trans Roy Soc Lond B 364:1107-1115

Yanega D (1997) Demography and sociality in halictine bees (Hymenoptera: Halictidae). In: Choe JC, Crespi BJ (eds) The evolution of social behavior in insects and arachnids. Cambridge University Press, Cambridge, pp 293-315 